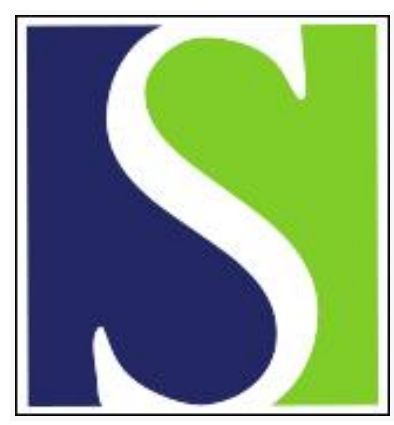

Scand J Work Environ Health 1977;3(3):128-134

https://doi.org/10.5271/sjweh.2784

Issue date: Sep 1977

Neuropathy and the automatic analysis of electromyographic signals from vibration exposed workers.

by Alaranta $H$, Seppäläinen AM

Key terms: automatic analysis; electromyographic signal; electromyography; EMG; exposed; nerve conduction velocity; neuropathy; traumatic vasospastic disease; vibration; vibration exposed worker; worker

This article in PubMed: www.ncbi.nlm.nih.gov/pubmed/198876 


\title{
Neuropathy and the automatic analysis of electromyographic signals from vibration exposed workers
}

\author{
by HANNU ALARANTA, M.D., and ANNA MARIA SEPPÄLÄINEN, M.D.1
}

\begin{abstract}
ALARANTA, H. and SEPPÄLÄINEN, A. M. Neuropathy and the automatic analysis of electromyographic signals from vibration exposed workers. Scand. j. work environ. \& health 3 (1977) 128-134. An automatic analysis of the electromyographic activity of the extensor digitorum communis, first dorsal interosseus and opponens pollicis muscles was performed, and both motor and sensory conduction velocities of the median and ulnar nerves were measured in the study of neuropathic changes that occur in traumatic vasospastic disease. Twenty-eight forest workers and 10 pneumatic-tool operators, all with a long occupational exposure to local vibration of the hands, were studied with these neurophysiological methods and general clinical and roentgenological examinations. Twenty male manual workers with a similar age distribution served as the comparison group. The most sensitive measures which separated the subjects with traumatic vasospastic disease from the nonexposed workers were the conduction velocity of the slower motor fibers of the ulnar nerve, the distal sensory conduction velocity and the motor distal latency of the median nerve. The duration and rise time of the averaged muscular potentials of intrinsic hand muscles correlated especially with those nerve conduction velocities which were the most sensitive in exhibiting neuropathic changes.
\end{abstract}

Key words: automatic analysis, electromyography, nerve conduction velocity, neuropathy, traumatic vasospastic disease.

A worker exposed to local vibration, for example, a lumberjack with a power saw or a miner using a pneumatic tool, may eventually develop traumatic vasospastic disease (TVD). TVD can involve various symptoms of the circulatory and nervous systems, muscles, tendons, and bones. Electroneuromyographic examinations have been used to show neuropathic changes in the nerve conduction velocities and electrical activity of the muscles of

1 Department of Occupational Medicine, Institute of Occupational Health, Helsinki, Finland.

Reprint requests to: Dr. A. M. Seppäläinen, Institute of Occupational Health, Haartmaninkatu 1, FIN-00290 Helsinki 29, Finland. persons with TVD and also of workers exposed to vibration $(2,8,9,10)$.

The voluntary electrical activity of the muscle - motor unit potentials - has recently been studied with the application of automatic analysis. Thus the parameters of the averaged muscular potential (AMP) have been defined and measured $(5,6,7)$. Using these parameters, scientists have noted differences between the AMPs of healthy, myopathic, and neuropathic muscles.

The aim of the present study was to gain more knowledge about the neuropathic changes that occur in TVD through an evaluation of AMP parameters and to compare different nerve conduction velocities and AMP parameters to see which of them are the most sensitive indices of early neuropathy. 


\section{MATERIAL}

The exposed group comprised 38 male workers aged 26 to 61 years (table 1 ) and occupationally exposed for 5 to 30 years (table 2) to local vibration of the hands. Twenty-eight of the men were forest workers who operated power saws and 10 were users of pneumatic tools, mainly rock drillers. All of the subjects had come to our institute to be examined because of suspected TVD. Over half of the subjects had been on the job within five months of the examination (table 2). The subjects were usually year-around workers exposed to vibration 5 to $7 \mathrm{~h}$ daily.

Table 1. Age distribution (years) of the vibration exposed and nonexposed workers.

\begin{tabular}{|c|c|c|c|c|c|c|}
\hline & \multicolumn{4}{|c|}{ Exposed subgroup a } & \multicolumn{2}{|c|}{$\begin{array}{c}\text { Nonexposed } \\
\text { group }\end{array}$} \\
\hline & 0 & 1 & 2 & $0-2$ & Total & $\begin{array}{c}\text { For } \\
\text { sub- } \\
\text { group } 2\end{array}$ \\
\hline $\begin{array}{l}\mathrm{N} \\
\text { Mean }\end{array}$ & 9 & 14 & 15 & 38 & 20 & 15 \\
\hline age & 36.8 & 43.3 & 49.5 & 44.1 & 42.6 & 46.8 \\
\hline SD & 6.4 & 10.6 & 7.1 & 9.6 & 11.2 & 9.7 \\
\hline
\end{tabular}

a Classification of the exposed subgroups: $0=$ normal neurophysiological findings, $1=$ borderline findings, and $2=$ polyneurophathic findings compatible with vibnation syndrome.

Table 2. Duration of the exposure to vibration of the subgroups a and the pause without exposure before the examination.

\begin{tabular}{|c|c|c|c|c|c|c|}
\hline & \multicolumn{3}{|c|}{ Years of exposure } & \multicolumn{3}{|c|}{$\begin{array}{c}\text { Months of } \\
\text { nonexposure } \\
\text { before exami- } \\
\text { nation }\end{array}$} \\
\hline & $\begin{array}{l}\text { Sub- } \\
\text { group }\end{array}$ & $\begin{array}{l}\text { Sub- } \\
\text { group }\end{array}$ & $\begin{array}{l}\text { Sub- } \\
\text { group }\end{array}$ & $\begin{array}{l}\text { Sub- } \\
\text { group }\end{array}$ & $\begin{array}{l}\text { Sub- } \\
\text { group }\end{array}$ & $\begin{array}{l}\text { Sub- } \\
\text { group }\end{array}$ \\
\hline & 0 & 1 & 2 & 0 & 1 & 2 \\
\hline $\mathrm{N}$ & 9 & 14 & 15 & 9 & 14 & 15 \\
\hline Range & $5-20$ & $8-30$ & $10-26$ & $0-12$ & $0-36$ & $0-36$ \\
\hline Median & 17 & 15 & 18 & 5 & 1.5 & 4 \\
\hline QI & 11 & 13 & 12 & 1 & 0 & 0 \\
\hline QIII & 17.5 & 15 & 21 & 8 & 7 & 7 \\
\hline
\end{tabular}

a See table 1 for the subgroup classifications.
Since earlier studies in this institute (10, 11) have indicated that the conduction velocity of the slower motor fibers (CVSF) of the ulnar nerve and the motor distal latency (DL) of the median nerve are the most sensitive measures showing vibration-induced neuropathy, we classified the exposed subjects into the following three subgroups based on these measures:

subgroup $0=$ normal CVSF of the ulnar nerve and DL of the median nerve, measured bilaterally;

subgroup 1 = borderline findings, e.g., only one CVSF of the ulnar nerve or DL of the median nerve abnormal;

subgroup $2=$ polyneuropathic findings compatible with vibration syndrome, e.g., at least two abnormal CVSF or DL findings, often in combination with neurogenic abnormalities in the clinical electromyographic (EMG) examination.

Twenty males, aged 27 to 63 years, formed the comparison group. They were manual workers without exposure to vibration or neurotoxic chemicals, neither did they suffer from any neurological diseases. The ages of the nonexposed workers did not differ significantly from those of the exposed ones, except for those in subgroup 2, in which no one was younger than 35. Therefore the statistical comparisons of the conduction velocity measures of subgroup 2 were performed so that only nonexposed subjects 35 years of age or older (table 1) were included, whereas corresponding comparisons of subgroup 0 and 1 or the combined findings of all the exposed included all of the nonexposed.

\section{METHODS}

The motor DL and the maximal motor conduction velocity (MCV) of the median and ulnar nerves were measured bilaterally according to common methods (13). The CVSF of the ulnar nerve was determined on the basis of partial antidromic blocking (12). The nerves were stimulated with a Disa stimulator and a skin electrode. The responses were picked up with skin electrodes and amplified by a Disa electromyograph. The sensory conduction velocity from the finger to the wrist (dSCV) and from the wrist to the elbow (SCV) was measured with the 


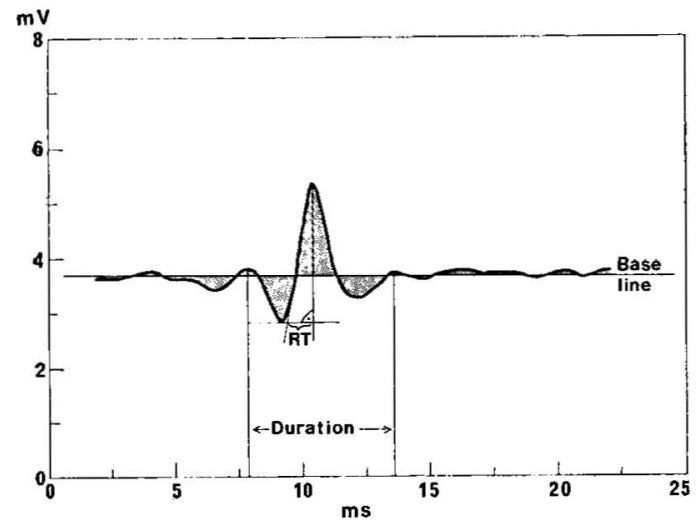

Fig. 1. Schematic representation of the method used to measure the rise time (RT) and duration of the averaged muscular potential and the area of the muscular potential as deviations from the baseline.

stimulating electrode located at the lateral aspect of the thumb and the ring finger, respectively, in the region of the digital nerve. Evoked nerve potentials were picked up with skin electrodes at the wrist and elbow, amplified by an electromyograph, and fed into a Pulse Analyser (Nokia Electronics), where 30 to 200 responses were averaged.

All the measurements were carried out in the same warm laboratory (temperature $25-26^{\circ} \mathrm{C}$ ). Skin temperature at the elbow level was measured with a Sekunden- thermometer Testoterm, and it was always higher than $30^{\circ} \mathrm{C}$.

EMG signals during slight or moderate muscle contraction were recorded from the extensor digitorum communis muscle, the first dorsal interosseus muscle, and the opponens pollicis muscle of the hand with the most symptoms, usually the left hand, with Disa coaxial needle electrodes and amplified by the Disa electromyograph; the results were visually evaluated. The EMG signals were fed through two separate lines into the Nokia Pulse Analyser. The EMG signal through the first line acted as a trigger pulse for a detector device, which determined the lower and upper limits of the amplitude of the signal to be analyzed; the second line fed the EMG to the signal averaging through a 10-ms delay line (Transient Store Model 512 A, Physical Data Inc.). Fifty motor unit potentials were averaged in digital form. A similar method has been previously described by Lang et al. (5). The AMP was recorded in analogical form with an Omnigraph XY writer. From the output, the total duration of the AMP and the rise time was measured; the latter has been described earlier by Viitasalo and Komi (14). The area of the muscular potential (as deviations from the baseline) was calculated from the digital output by a program run on a Wang 2200 computer. The baseline was determined as the electrical mean of the total EMG activity

Table 3. Means (M) and standard deviations (SD) of skin temperatures (T), motor distal latencies (DL) and conduction velocities of the median nerve (MCV = maximal motor conduction velocity, $\mathrm{SCV}=$ sensory conduction velocity from wrist to elbow, dSCV $=$ sensory conduction velocity from finger to wrist), determined for the exposed subgroups and the nonexposed group.

\begin{tabular}{|c|c|c|c|c|c|c|c|c|c|c|c|}
\hline \multirow[t]{2}{*}{ Group } & \multirow[t]{2}{*}{$\mathrm{N}$} & \multicolumn{2}{|c|}{$\mathrm{T}\left({ }^{\circ} \mathrm{C}\right)$} & \multicolumn{2}{|c|}{$\mathrm{DL}$ (ms) } & \multicolumn{2}{|c|}{$\operatorname{MCV}(\mathrm{m} / \mathrm{s})$} & \multicolumn{2}{|c|}{$\operatorname{SCV}(\mathrm{m} / \mathrm{s})$} & \multicolumn{2}{|c|}{$\mathrm{dSCV}(\mathrm{m} / \mathrm{s})$} \\
\hline & & M & $\mathrm{SD}$ & $\mathrm{M}$ & $\mathrm{SD}$ & $\mathrm{M}$ & $\mathrm{SD}$ & M & $\mathrm{SD}$ & MI & $\mathrm{SD}$ \\
\hline \multicolumn{12}{|l|}{ Exposed a } \\
\hline subgroup 0 & 9 & 32.7 & 0.8 & 4.0 & 0.5 & 63.5 & 7.1 & 62.0 & 3.3 & 48.1 & 4.0 \\
\hline subgroup 1 & 14 & 32.4 & 0.8 & 4.1 & 0.6 & 58.8 & 6.8 & 59.5 & 4.7 & $46.3^{*}$ & 4.1 \\
\hline subgroup 2 & 15 & 32.7 & 1.1 & $4.8 * *$ & 0.8 & 54.7 & 5.1 & $55.3^{*}$ & 4.9 & $39.6^{* * *}$ & 5.9 \\
\hline subgroups $0-2$ & 38 & 32.6 & 0.9 & $4.3 * *$ & 0.7 & 58.3 & 7.0 & $58.6^{*}$ & 5.1 & $44.2^{* * *}$ & 6.0 \\
\hline \multicolumn{12}{|l|}{ Nonexposed } \\
\hline total & 20 & 32.2 & 0.6 & 3.9 & 0.7 & 59.0 & 4.9 & 62.1 & 7.1 & 50.1 & 5.1 \\
\hline for subgroup 2 & 15 & 32.2 & 0.6 & 4.0 & 0.4 & 58.1 & 5.4 & 59.9 & 6.5 & 49.3 & 5.3 \\
\hline
\end{tabular}

a See table 1 for the subgroup classifications.

* $\mathrm{p}<0.05 ;{ }^{* *} \mathrm{p}<0.01 ; \quad * * * \mathrm{p}<0.001$ (Student's t-test). 
Table 4. Means (M) and standard deviations (SD) of skin temperatures (T), motor distal latencies (DL) and conduction velocities of the ulnar nerve (MCV = maximal motor conduction velocity, $\mathrm{CVSF}=$ conduction velocity of slower motor fibers, SCV $=$ sensory conduction velocity from wrist to elbow, dSCV = sensory conduction velocity from finger to wrist), determined for the exposed subgroups and the nonexposed group.

\begin{tabular}{|c|c|c|c|c|c|c|c|c|c|c|c|c|c|}
\hline \multirow[t]{2}{*}{ Group } & \multirow[t]{2}{*}{$\mathrm{N}$} & \multicolumn{2}{|c|}{$\mathrm{T}\left({ }^{\circ} \mathrm{C}\right)$} & \multicolumn{2}{|c|}{ DL (ms) } & \multicolumn{2}{|c|}{$\mathrm{MCV}(\mathrm{m} / \mathrm{s})$} & \multicolumn{2}{|c|}{$\operatorname{CVSF}(\mathrm{m} / \mathrm{s})$} & \multicolumn{2}{|c|}{$\mathrm{SCV}(\mathrm{m} / \mathrm{s})$} & \multicolumn{2}{|c|}{$\mathrm{dSCV}(\mathrm{m} / \mathrm{s})$} \\
\hline & & M & $\mathrm{SD}$ & M & $\mathrm{SD}$ & M & $\mathrm{SD}$ & M & $\mathrm{SD}$ & MI & $\mathrm{SD}$ & $\mathrm{M}$ & $\mathrm{SD}$ \\
\hline \multicolumn{14}{|l|}{ Exposed a } \\
\hline subgroup 0 & 9 & 32.3 & 0.6 & 3.3 & 0.4 & 60.8 & 7.0 & 44.8 & 3.9 & 62.8 & 3.8 & 53.6 & 2.6 \\
\hline subgroup 1 & 14 & 32.6 & 1.0 & 3.4 & 0.5 & 57.2 & 4.1 & $40.4 * * *$ & 2.9 & 57.0 & 5.7 & 50.7 & 4.7 \\
\hline $\begin{array}{l}\text { subgroup } 2 \\
\text { subgroups }\end{array}$ & 15 & 32.6 & 0.8 & 3.7 & 0.4 & 56.0 & 5.9 & $36.7 * * *$ & 4.7 & $52.1 * *$ & 5.6 & 48.3 & 5.4 \\
\hline $0-2$ & 38 & 32.5 & 0.9 & 3.5 & 0.5 & 57.8 & 6.1 & $40.0^{* * *}$ & 4.9 & 56.7 & 6.6 & $50.4^{*}$ & 4.9 \\
\hline \multirow{3}{*}{$\begin{array}{l}\text { Nonexposed } \\
\text { total } \\
\text { for sub- } \\
\text { group } 2\end{array}$} & & & & & & & & & & & & & \\
\hline & 20 & 32.3 & 0.8 & 3.5 & 0.4 & 59.1 & 6.2 & 45.4 & 4.5 & 59.3 & 7.3 & 53.7 & 6.4 \\
\hline & 15 & 32.3 & 0.9 & 3.5 & 0.5 & 57.3 & 3.8 & 45.2 & 4.9 & 57.7 & 6.5 & 51.9 & 5.5 \\
\hline
\end{tabular}

a See table 1 for the subgroup classifications.

${ }^{*} \mathrm{p}<0.05 ;{ }^{* *} \mathrm{p}<0.01 ; \quad{ }^{* * *} \mathrm{p}<0.001$ (Student's t-test).

during the period of analysis (fig. 1). We analyzed two or three AMPs from each muscle of each subject, and the mean values of the individual AMPs were used in the statistical calculations.

In addition to the neurophysiological examination all the exposed subjects underwent diagnostic procedures which are generally applied at our institute in cases of suspected TVD. They include a thorough occupational and medical history, a clinical, orthopedic and neurological examination, and X-rays of the hands, elbows, shoulders and, in certain cases, the cervical spine. The final clinical diagnosis is based on all the findings acquired in the examinations and on the acquired data on the exposure.

\section{RESULTS}

The exposed workers had statistically significantly slower CVSFs of the ulnar nerve $(p<0.001)$ and dSCVs of the median nerve $(p<0.001)$, longer $D L s$ of the median nerve $(p<0.01)$, and slightly slower dSCVs of the ulnar nerve $(p<0.05)$ and SCVs of the median nerve $(p<0.05)$ than the nonexposed as a group. All the nerve conduction velocities were increasingly slower and motor distal latencies increasingly longer from subgroup 0 to subgroup 2 (tables 3 and 4). This finding was partly based on classification in regard to the CVSF of the ulnar nerve and the DL of the median nerve.

The skin temperatures at the proximal stimulation points did not differ statistically significantly between the exposed subgroups and the comparison group (tables 3 and 4).

There was a tendency for the duration and rise time of the AMP to be longer in subgroup 2 than in the comparison group although the only statistically significant difference was noted for the duration of the AMP of the first dorsal interosseus muscle (tables 5 and 6).

We also studied the relationships between AMP parameters and nerve conduction measures, taking into account all the exposed and nonexposed subjects. The clearest correlations were noted between the AMP of the first dorsal interosseus muscle and the CVSF of the ulnar nerve. The slower the CVSF of the ulnar nerve, the longer the rise time of the AMP of the first dorsal interosseus muscle ( $\mathrm{r}=-0.42$, $p<0.001$ ) (fig. 2). Similarly the duration of the AMP was longer when the CVSF became slower $(\mathrm{r}=-0.34, \mathrm{p}<0.01)$. Some correlation was also noted between the areas of the AMP and the CVSF ( $\mathrm{r}=$ $-0.29, \mathrm{p}<0.05$ ). The duration and rise 
Table 5. Means (M) and standard deviations (SD) of the rise time (ms) of the averaged muscular potentials of the opponens pollicis muscle, the first dorsal interosseus muscle, and the extensor digitorum communis muscle, determined for the exposed subgroups and the nonexposed group.

\begin{tabular}{|c|c|c|c|c|c|c|}
\hline \multirow[t]{2}{*}{ Group } & \multicolumn{2}{|c|}{$\begin{array}{l}\text { Opponens } \\
\text { pollicis } \\
\text { muscle }\end{array}$} & \multicolumn{2}{|c|}{$\begin{array}{c}\text { First dorsal } \\
\text { interosseus } \\
\text { muscle }\end{array}$} & \multicolumn{2}{|c|}{$\begin{array}{l}\text { Extensor } \\
\text { digitorum } \\
\text { communis } \\
\text { muscle }\end{array}$} \\
\hline & M & $\mathrm{SD}$ & M & $\mathrm{SD}$ & $\mathrm{M}$ & SD \\
\hline \multicolumn{7}{|l|}{ Exposed a } \\
\hline subgroup 0 & 0.80 & 0.30 & 0.83 & 0.44 & 0.72 & 0.29 \\
\hline subgroup 1 & 0.97 & 0.47 & 0.76 & 0.28 & 0.72 & 0.40 \\
\hline subgroup 2 & 0.89 & 0.35 & 0.91 & 0.37 & 0.80 & 0.37 \\
\hline \multicolumn{7}{|l|}{ Nonexposed } \\
\hline total & 0.77 & 0.31 & 0.71 & 0.28 & 0.65 & 0.31 \\
\hline for subgroup 2 & 0.73 & 0.32 & 0.72 & 0.28 & 0.64 & 0.32 \\
\hline
\end{tabular}

a See table 1 for the subgroup classifications.

Table 6. Means (M) and standard deviations (SD) of the duration (ms) of the averaged muscular potentials of the opponens pollicis muscle, the first dorsal interosseus muscle and the extensor digittorum communis muscle, determined for the exposed subgroups and the nonexposed group.

\begin{tabular}{|c|c|c|c|c|c|c|}
\hline \multirow[t]{2}{*}{ Group } & \multicolumn{2}{|c|}{$\begin{array}{l}\text { Opponens } \\
\text { pollicis } \\
\text { muscle }\end{array}$} & \multicolumn{2}{|c|}{$\begin{array}{c}\text { First dorsal } \\
\text { interosseus } \\
\text { muscle }\end{array}$} & \multicolumn{2}{|c|}{$\begin{array}{l}\text { Extensor } \\
\text { digitorum } \\
\text { communis } \\
\text { muscle }\end{array}$} \\
\hline & $\mathrm{M}$ & $\mathrm{SD}$ & M & $\mathrm{SD}$ & $\mathrm{M}$ & $\mathrm{SD}$ \\
\hline \multicolumn{7}{|l|}{ Exposed a } \\
\hline subgroup 0 & 7.18 & 1.52 & 7.40 & 2.61 & 7.36 & 3.40 \\
\hline subgroup 1 & 7.37 & 1.72 & 7.10 & 2.05 & 6.36 & 2.17 \\
\hline subgroup 2 & 7.33 & 2.11 & $8.05 * *$ & 1.71 & 7.65 & 2.41 \\
\hline \multicolumn{7}{|l|}{ Nonexposed } \\
\hline total & 6.55 & 1.37 & 6.16 & 1.77 & 6.94 & 2.43 \\
\hline for subgroup 2 & 6.37 & 1.44 & 5.95 & 1.80 & 6.81 & 2.49 \\
\hline
\end{tabular}

a See table 1 for the subgroup classifications.

$* * \mathrm{p}<0.005$.

time of the AMP of the first dorsal interosseus muscle and the dSCV of the ulnar nerve showed a negative correlation $(\mathrm{r}=$ -0.28 and $\mathrm{r}=-0.27$, respectively, $\mathrm{p}<$ 0.05). The AMP of the opponens pollicis muscle showed a weaker correlation to the conduction velocity measures of the median nerve. The rise time of the AMP was increasingly longer with increasingly slower MCVs $(r=-0.31, p<0.05)$. The duration of the AMP was longer with the increasingly longer DLs $(\mathrm{r}=+0.29, \mathrm{p}<$ 0.05 ) or with the slower dSCVs ( $\mathrm{r}=$ $-0.28, \mathrm{p}<0.05$ ).
The final clinical diagnosis concerning occupational disease, i.e., traumatic vasospastic disease, in the different neurophysiological subgroups is presented in table 7. Nearly all of the subjects in subgroup 2 were diagnosed as having TVD. In only one case could this diagnosis not be ascertained on clinical grounds, and the subject is to be kept under observation for the next two years. The proportion of TVD was less in the other groups, and only three out of the nine neurophysiologically normal workers (subgroup 0) were diagnosed as having TVD. 


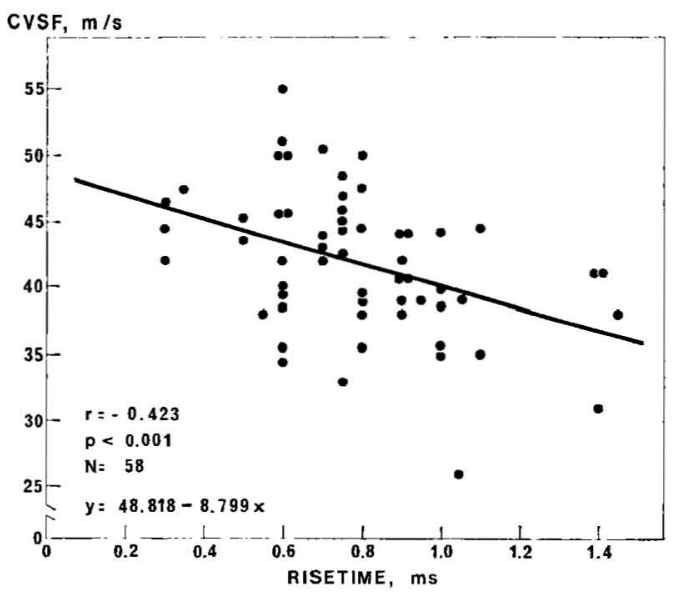

Fig. 2. The conduction velocities of the slower motor fibers (CVSF) of the ulnar nerve plotted against the rise times of the averaged muscular potentials of the first dorsal interosseus muscles and the linear regression line. All the exposed and nonexposed subjects were taken into account in the calculations.

\section{DISCUSSION}

Experimental studies have shown that local vibration causes pathomorphological changes - primarily Wallerian degeneration - in the peripheral nerves of rabbits $(1,3)$. In humans, neuropathy can be demonstrated as the slowing of nerve conduction velocities. The slowing of the $\mathrm{MCV}$ in the arm nerves of workers occupationally exposed to vibration has been shown by Dylewska (2) and Lukáš and Kužel (8). In her studies Dylewska (2) found that the SCV of the arm nerves was

Table 7. The clinical diagnosis concerning traumatic vasospastic disease (TVD) in the neurophysiological subgroups of the exposed workers.

\begin{tabular}{lccr}
\hline & \multicolumn{3}{c}{ Subgroup b } \\
\cline { 2 - 4 } TVD & 0 & 1 & 2 \\
\hline Positive & 3 & 7 & 14 \\
Questionable a & 2 & 4 & 1 \\
Negative & 4 & 3 & 0 \\
\hline Total & 9 & 14 & 15 \\
\hline
\end{tabular}

a TVD not yet clinically ascertained, but enough symptoms or signs exist to recommend further observation after one or two years.

b See table 1 for the subgroup classifications. more often reduced than the MCV among workers who had operated pneumatic tools. In our institute previous field studies (10) on motor nerve function have shown that the CVSF of the ulnar nerve and the DL of the median nerve were affected the most often among lumberjacks operating power saws.

In the present study we measured both sensory and motor conduction velocities of the arm nerves. In accordance with previous reports, the CVSF of the ulnar nerve was a potent factor in differentiating the vibration exposed workers from those nunexposed. The next most powerful factors were the distal SCV and the motor DL of the median nerve, both of which reflect damage in the distal portion of the median nerve. Abnormal SCVs in the forearm section were only slightly slower, and such abnormality was usually noted only among the workers with the most pronounced neuropathic signs. The SCVs were, however, more reduced than the MCVs, since the MCVs did not show any significant decrease in any subgroup of the exposed workers.

In neuropathy certain so-called neurogenic changes are noted in motor unit potentials in electromyography. The duration of the motor unit potential increases and, especially in the regenerative phase, the amplitude of the motor unit potential may increase. Therefore the duration and rise time of the AMP can be expected to increase in neuropathy. An increased duration and a possible increase in amplitude would lead to an enlargement of the area of the AMP, as shown also by Lang and Tuomola (6). A tendency towards an increasing duration and rise time of the A.MP was noted in subgroup 2, in which the nerve conduction velocities were the slowest. The area of the AMP did not show any significant changes in the exposed workers when they were compared to the nonexposed ones. In all of the AMP measures, however, the interindividual, and at times also the intraindividual, variation was relatively large. One must remember that we tried to register different motor units in consecutive measurements of the same muscles to achieve a better sampling. Komi and Viitasalo (4) have shown that the parameters of AMPs registered with a surface 
electrode, especially the amplitude, greatly depend on the level of the muscle tension. The rise time of the AMP seemed, however, to be relatively stable with a tension force of 40 to $80 \%$ of the maximal force. The tension range during our AMP recordings fell into this category, so we do not believe that our variations reflect variations in muscle tension.

The rise time and the duration of the AMP correlated with the CVSF of the ulnar nerve throughout the large variation of the CVSF; the latter is a sensitive factor characterizing neuropathy. Similar tendencies were noted for the distal SCVs of both the median and ulnar nerves and the AMPs of muscles supplied by these nerves. Thus correlations were noted between certain AMP parameters and those nerve conduction velocities which were the most sensitive in differentiating vibration induced neuropathy. These facts support the presumption that, indeed, measureable changes occur in AMPs in early stages of neuropathy. Although this preliminary study did not prove that AMP parameters are highly sensitive measures of early vibration-induced neuropathy, further studies on AMP parameters are indicated to determine whether they can be used in the development of methods for the early diagnosis of occupational nerve injuries.

Neurophysiological studies play a leading role in showing the neuropathic changes of TVD; this is also noted from the good correlation found between the neurophysiological classification and the final diagnosis of clinical TVD. However, neuropathy is not always the first sign of TVD. On the other hand, if neuropathic signs appear, the continuation of work with vibration exposure is to be allowed only with caution.

\section{REFERENCES}

1. ANDREEVA-GALANINA, E. T. and KAR-
POVA, N. I. [On degeneration and regeneration of peripheral nerves under the effect of experimental vibration]. Gig. $t r$. prof. zabol. 13 (1969): 2, 4-7. (In Russian)

2. DYLEWSKA, D. [The study of conduction in the motor and sensory nerves of upper limbs in vibration disease]. Neurol. neurochir.pol. 4 (1970): 1, 28-31. (In Polish)

3. KARPOVA, N. I. [Histopathology of the peripheral nerve stems subjected to the action of vibration]. Arkh.patol. 7 (1963) 49-53. (In Russian)

4. KOMI, P. V. and VIITASALO, J. H. T. Signal characteristics of EMG at different levels of muscle tension. Acta physiol. scand. 96 (1976) 267-276.

5. LANG, A. H., NURKKANEN, P. and VAAHTORANTA, K. M. Automatic sampling and averaging of electromyogarphic unit potentials. Electroencephalogr. clin. neurophysiol. 31 (1971) 404-406.

6. LANG, A. $H$. and TUOMOLA, H. $O$. Averaging and automatic analysis of EMG signals. Scand. j. rehabil. med. (1974): suppl. $3,33-36$.

7. LANG, A. H. and VAAHTORANTA, K. M. The baseline, the time characteristics and the slow afterwaves of the motor unit potential. Electroencephalogr. clin. neurophysiol. 35 (1973) 387-394.

8. LUKA.S, E. and KUŽEL, V. Klinische und elektromyographische Diagnostik der Schädigung des peripheren Nervensystems durch lokale Vibration. Int. Arch. Arbeitsmed. 28 (1971) $239-249$.

9. SEPPÄLÄINEN, A. M. Nerve conduction in the vibration syndrome. Work-environ.health 7 (1970) 82-84.

10. SEPPÄLÄINEN, A. IV. Peripheral neuropathy in forest workers: A field study. Work-environ-health 9 (1972) 106-111.

11. SEPPÄLÄINEN, A. M. Neurophysiological detection of vibration syndrome in the shipbuilding industry. In: O. KORHONEN (ed.), Vibration and work. Institute of Occupational Health, Helsinki, 1976, pp. 6371.

12. SEPPÄLÄNEN, A. M. and HERNBERG, S. Sensitive technique for detecting subclinical lead neuropathy. $B r . j$. ind. med. 29 (1972) 443-449.

13. SMORTO, M. P, and BASMAJIAN, J. V. Clinical electroneurography. Williams and Wilkins, Baltimore, Md. 1972. 234 p.

14. VIITASALO, J. H. and KOMI, P. V. Signal characteristics of EMG with special reference to reproducibility of measurements. Acta physiol. scand. 93 (1975) 531-539. 